\title{
Urban transmission of Chagas disease in Cochabamba, Bolivia
}

\author{
N Medrano-Mercado/1, R Ugarte-Fernandez, V Butrón, S Uber-Busek, HL Guerra', \\ Tania C de Araújo-Jorge ${ }^{2 /+}, \mathbf{R}$ Correa-Oliveira ${ }^{3}$
}

\begin{abstract}
Faculdade de Ciencias y Tecnología, Departamento de Biología, Laboratorio de Chagas e Inmunoparasitologia, Universidad Mayor de San Simón, Cochabamba, Bolivia ${ }^{2}$ Laboratório de Biologia Celular, Instituto Oswaldo Cruz-Fiocruz, Av. Brasil 4365, 21045-900 Rio de Janeiro, RJ, Brasil ${ }^{3}$ Laboratório Imunologia Celular e Molecular, Instituto René Rachou-Fiocruz, Belo Horizonte, MG, Brasil
\end{abstract}

Chagas disease is a major public health problem in Bolivia. In the city of Cochabamba, 58\% of the population lives in peripheral urban districts ("popular zones") where the infection prevalence is extremely high. From 1995 to 1999, we studied the demographics of Chagas infections in children from five to 13 years old $(n=2218)$ from the South zone (SZ) and North zone (NZ) districts, which differ in social, environmental, and agricultural conditions. Information gathered from these districts demonstrates qualitative and quantitative evidence for the active transmission of Trypanosoma cruzi in urban Cochabamba. Seropositivity was high in both zones (25\% in SZ and 19\% in NZ). We observed a high risk of infection in children from five to nine years old in $S Z$, but in NZ, a higher risk occurred in children aged 10-13, with odds ratio for infection three times higher in NZ than in SZ. This difference was not due to triatomine density, since more than 1,000 Triatoma infestans were captured in both zones, but was possibly secondary to the vector infection rate (79\% in SZ and 37\% in NZ). Electrocardiogram abnormalities were found to be prevalent in children and pre-adolescents $(S Z=40 \%, N Z=17 \%)$, indicating that under continuous exposure to infection and re-infection, a severe form of the disease may develop early in life. This work demonstrates that $\mathrm{T}$. cruzi infection should also be considered an urban health problem and is not restricted to the rural areas and small villages of Bolivia.

Key words: Chagas Disease - acute phase - risk factors - children - Bolivia - EKG abnormalities

Chagas disease, caused by infection with the flagellate Trypanosoma cruzi, represents a major public health problem in Latin America (Dias 2007). The prevalence of $T$. cruzi infection in Bolivia is one of the highest in South America (Valencia 1990, Guillén 2002) and 1.1 to 1.8 million people is believed to be infected with this parasite (more than $15 \%$ of the stated population in 1990). Prior to initiation of a national vector and transfusion control program in 2000, infection rates in Bolivia varied from 26 to $71 \%$ in children between one to six years old, and from 32 to $93.5 \%$ in adults, depending on the endemic area (Noireau 1999). Fifty-five percent of the national territory in Bolivia $\left(\sim 600 \mathrm{~km}^{2}\right)$ is endemic for Chagas disease, with approximately 3.5 million people at risk of infection (SNS 1994). In blood banks, up to $63 \%$ of potential donors were determined to be seropositive for T. cruzi antigens (Carrasco et al. 1990). The infection occurs in many different geographic areas and affects primarily the lowest socioeconomic population. Seven out of the nine Bolivian departments are endemic for Chagas disease, regardless of their altitude (WHO 2002). In highly endemic communities, such as the departments of Cochabamba, Chuquisaca, Tarija, and Santa Cruz, seroprevalence rates can reach $100 \%$ in older individuals (Arata et al. 1994). In endemic areas, children are exposed to $T$. cruzi vectors at an early age, and high

Financial support: PAPES-Fiocruz, IOC-Fiocruz, CNPq, FAPERJ + Corresponding author: taniaaj@ioc.fiocruz.br

Received 25 November 2007

Accepted 25 July 2008 prevalence rates are reported in individuals less than 10 years old. In the village of Tabacal, $40 \%$ of infected children fall within this age group (Pless et al. 1992 ), and in the village of Mizque, a study reported $11.8 \%$ and $44.1 \%$ prevalence rates for children aged from one to five and six to 10 years old, respectively (Brenière et al. 2002).

The city of Cochabamba (CO) is situated in Central Bolivia and has a population of about 752,613 (INE 2001). In previously published work, Laserna (1995) observed that $55 \%$ of the population in $\mathrm{CO}$ originates from other cities, and $70 \%$ of the population had emigrated from rural areas. In fact, immigrants accounted for $30 \%$ of the total population (Ledo \& Zelada 1989, INE 2001, Blanes 2006), and this is most likely secondary to political, economic, and social causes (Bailey-Lazcano \& TrewhellaFernandez 1998). Individuals immigrated to the urban zone in pursuit of a better quality of life and improved conditions for their families (Calderon \& Toranzos 1984).

Bolivia is currently undergoing the process of urbanization, and the rural population has decreased from $58.5 \%$ in 1976 to approximately $42 \%$ in 1992 (INE 2001). Peripheral districts or "popular zones" are home to 58\% of the city's population (Bailey-Lazcano \& TrewhellaFernandez 1998). The majority of people living in these districts $(40 \%)$ originates from rural villages and may act to transport triatomine vectors from rural to urban areas. Despite the fact that Chagas disease is classically considered to be a rural illness, it may also become an urban disease. Arata et al. (1994) have reported a serological infection prevalence of $17.5 \%$ in a female population composed of 2,850 individuals. The prevalence was determined to vary by age: $4.6 \%$ infection prevalence in infants younger than one year old, $7.2 \%$ in children aged 
one to four years old, $16 \%$ in children aged five to nine years old and $22.9 \%$ in individuals 15 to 44 years of age. The San Simon University created an Inter-Institutional Committee for the Control of Chagas disease in periurban districts of $\mathrm{CO}$ and demonstrate a prevalence of $39.6 \%$ and $62.2 \%$ (H Gonzáles, unpublished observations) in two particular areas: Nova Santa Veracruz and Villa San Andrés, respectively. Recent work by Cortez et al. (2006) clearly describes the conditions of the wild bug infestation in the region of $\mathrm{CO}$.

In the present paper, we evaluated the seropositivity of children from two geographically [North (NZ) and South (SZ) zones], socially, and economically distinct urban regions of urban $\mathrm{CO}$ with the aims of answering the following questions: is there any difference between seropositivity for Chagas disease in regions with different socio-economic profiles? What is the clinical status of the infected population in regards to cardiac pathology? What are the risk factors for Chagas infection in these populations?

\section{PATIENTS, MATERIALS AND METHODS}

Study area - Two districts in the periphery of CO (Fig. 1A, B), the SZ (Valle Hermoso) and NZ (Temporal) (Fig. 1) were chosen for the study based on geographic, social, and economic differences. The general characteristics of the families living in the peripheral districts or "popular zones" are as follows (Bailey-Lazcano \& Trewhella-Fernandez 1998): (a) all are migrants, and most are second or third generation (e.g., in the SZ, 55\% were born in the $\mathrm{CO}, 10.5 \%$ were from rural villages in the same district, and the remainder were from other districts); (b) basic public services are scarce and living conditions are poor; (c) most of the families are in the lower socioeconomic class and live in precarious houses with inconsistent access to health and education; (d) the families have several children; (e) the mother is the head of the household, generally working as an informal salesperson on the streets while their husbands are working in $\mathrm{CO}$ or

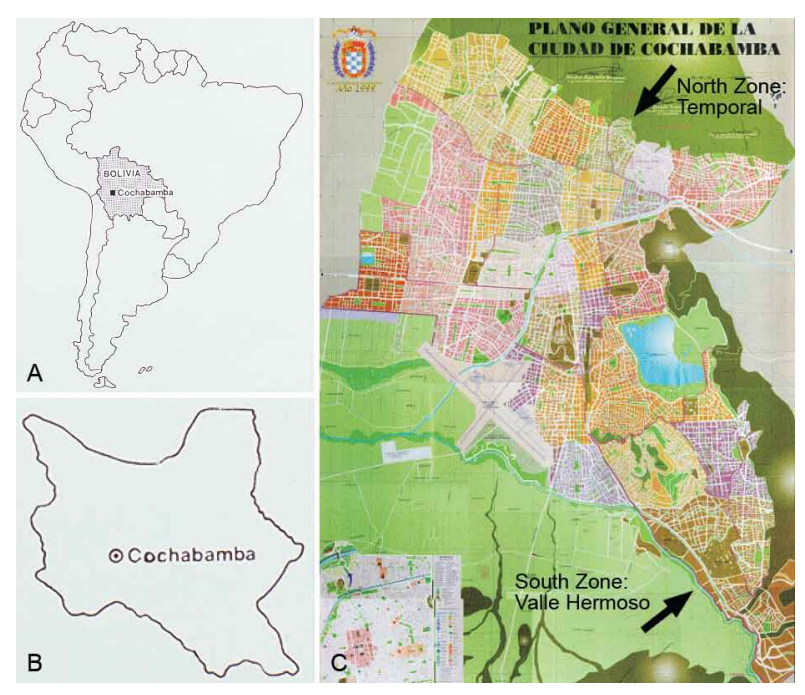

Fig. 1: map of Soth America (A), showing the location of Bolivia, department and city of Cochabamba (B) and the two studied areas (C) of Velle Hermoso and Temporal, in the South and North zones, respectively. other cities; (f) the educational background of parents is minimal; and $(\mathrm{g})$ there is a high frequency of malnourished children. As for the history of the two areas, both of them have the following in common: (a) the fact that the districts were previously farm land that was slowly transformed into an urban area; and (b) a significant immigrant population (from Oruro and Potosi in the SZ and from country villages of $\mathrm{CO}$ in the NZ). The districts chosen for the study differ in the following: (a) the social conditions, which are superior in the NZ as compared to the $\mathrm{SZ}$ as indicated by better general living conditions and higher educational levels; (b) the environmental conditions, with a drier climate in the SZ than in the NZ; and (c) agricultural resources, which are present in the NZ and absent in the SZ (Sostres \& Delgado 1993).

Individuals and blood samples - In this study, 2,218 children were examined with ages ranging from five to 13 years old (Fig. 2A). Of the data collected, 899 individuals were living in the SZ and 1,319 in the $\mathrm{NZ}$ of CO. Identification of the study population was conducted during 1995 to 1996 (SZ) and 1996 to 1999 (NZ). The subjects were recruited during regular school attendance in both districts. To introduce the study, we presented several seminars (Fig. 2B) for the students, parents (Fig. 2C), and teachers as well as for the directors of the school board in order to obtain an effective collaboration. The aim of these seminars was to inform the individuals about the importance of Chagas disease in Bolivia, as well as to share with them the objectives of the research project. Prior to inclusion in this study, formal written informed consent was obtained from all parents or guardians for blood collection, clinical examination, and treatment of the involved children. Blood donation was voluntary, and treatment was offered to all individuals with positive serum reactivity to T. cruzi independent of their participation in the study. For the serological studies, $2 \mathrm{ml}$ of blood was collected from each child, separated by centrifugation, and the serum obtained was used for serological assays in the same day. Clinical examination and electrocardiogram (EKG) were performed by two of the authors (R U-F, V B) for all individuals (Fig. 2D). Each physician completed a distinct set of forms, which included identification of the individual, epidemiological and clinical information, the EKG reading, and serological data. Both of the authors read the EKG profiles in order to confirm the results. Serum samples of dogs living in the SZ were collected and analyzed by indirect hemagglutination assay (IHA) assays. This study was approved by the Fiocruz Ethics Committee in Research, according to the Brazilian resolution 196/96.

Serology with IHA and direct enzyme-linked immunosorbent assay (ELISA) - IHA was performed using a commercially available diagnostic kit (Polychaco, Buenos Aires, Argentina). The serum was diluted 1/16, $1 / 32$, and $1 / 64$, and positive and negative controls were employed for all test plates. This assay was also used to analyze the dog serum samples. ELISA was performed using a commercial available kit (Chagastest, Buenos Aires, Argentina) and as with the IHA analysis, positive and negative controls provided in the kit were used with all samples. 
Statistical analysis - All information obtained in this study was transcribed into a data base and statistical analyses performed using SAS (Statistical Analysis Software ${ }^{\circledR}$ ) or Statistica for Windows (StatSoft). Logistic regression analyses were performed by one of the authors (HLG).
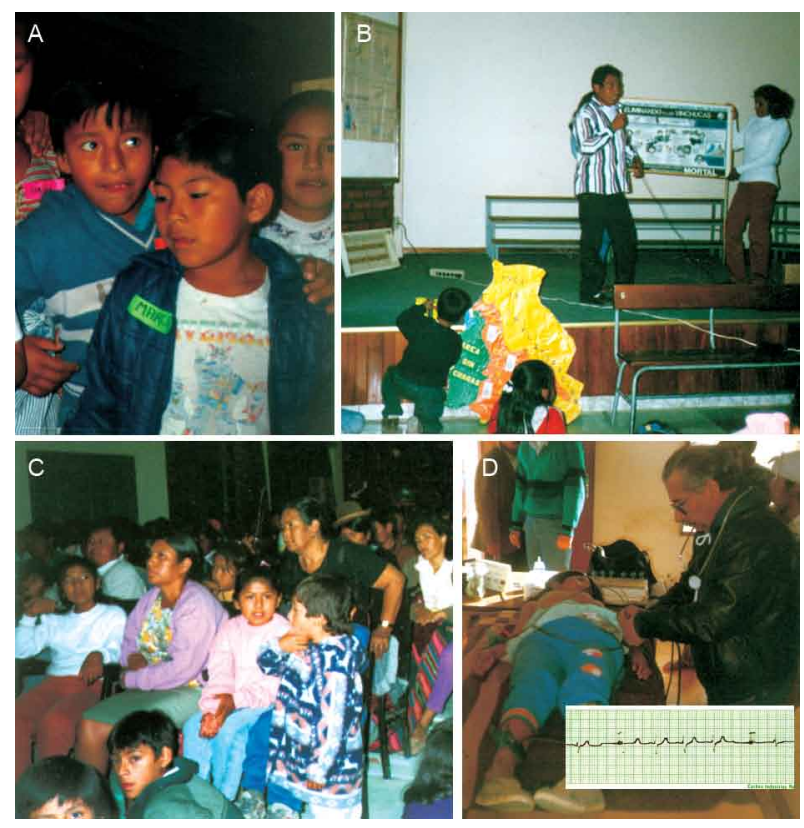

Fig. 2: general aspects of the participating children (A), and of the seminars $(\mathrm{B}, \mathrm{C})$ conducted for parents, the children, the teachers and school authorities, that allowed approach of 2,218 children, even for electrocardiographical study (D).

\section{RESULTS}

Social and epidemiological profile of the population under study - Table I demonstrates that the SZ cohort accounted for $40.6 \%$ (902) and the NZ cohort for $59.4 \%$ $(1,319)$ of the study population. The mean number of persons per family was similar (6 to 7 persons) in both zones. However, large families composed of 20 or more individuals were reported in both the SZ and NZ. The number of children attending school was also similar between the districts, with a mean of four individuals per family. The majority of the children in both areas demonstrated a basic knowledge of triatomine vectors (93.8\% in the SZ, and $95.6 \%$ in the NZ), and only a small number of children did not know about the insect (56 out of 902 in the SZ, and 57 out of 1,319 in the NZ). When asked about the cause of the disease, more than $99 \%$ of the children attributed Chagas disease to the triatomine (vinchuca, in the local language). Even after informative seminars, the children did not retain the provided information that $T$. cruzi is the etiological agent in Chagas disease (only 13/2,218 answers named the parasite as the cause of Chagas disease). In the NZ, a small number of children $(13 / 2,221 ; 0.6 \%)$ reported the occurrence of Romaña's sign once in their lifetime and no report of this sign was given in the SZ.

When the children were asked to describe their housing conditions, a distinct difference appeared between the two areas studied (Table II, Fig. 3). Children living in the SZ (Fig. 3A-C) reported predominance of old houses $(93.8 \%)$ and both walls and floors were made of mud (Fig. 3B, C). Among the old houses in the NZ, most contained cement floors $(96.9 \%$, Fig. 3D-F), while only $3.1 \%$ had earth floors. The houses differed also in ceiling con-

TABLE I

Social profile and Chagas disease where urban Trypanosoma cruzi infection was studied

\begin{tabular}{|c|c|c|c|}
\hline Parameter & South Zone Valle Hermoso & North Zone Temporal & Total \\
\hline Houses studied [n (\%)] & $899(40.6)$ & $1,319(59.4)$ & $2,218(100)$ \\
\hline \multicolumn{4}{|l|}{ Persons per family } \\
\hline mean $\pm \mathrm{sd}$ & $6.8 \pm 2.7$ & $6.9 \pm 2.7$ & $6.9 \pm 2.7$ \\
\hline range & $2-21$ & $2-21$ & $2-21$ \\
\hline \multicolumn{4}{|l|}{ Children going to school } \\
\hline mean $\pm \mathrm{sd}$ & $4.1 \pm 2.1$ & $4.1 \pm 2.1$ & $4.1 \pm 2.1$ \\
\hline range & $2-14$ & $1-14$ & $1-14$ \\
\hline \multicolumn{4}{|c|}{ Knowledge about Chagas disease [n (\%)] } \\
\hline Yes & $879(97.5)$ & $1,291(97.8)$ & $2,170(97.7)$ \\
\hline No & $23(2.5)$ & $28(2.2)$ & $51(2.3)$ \\
\hline \multicolumn{4}{|c|}{ Knowledge about the insect vector $[\mathrm{n}(\%)]$} \\
\hline Yes & $846(93.8)$ & $1,262(95.6)$ & $2,108(94.9)$ \\
\hline No & $56(6.2)$ & $57(4.4)$ & $113(5.1)$ \\
\hline \multicolumn{4}{|c|}{ Association of the parasite and the vector as the cause of Chagas disease [n (\%)] } \\
\hline T. cruzi & 0 & $9(0.7)$ & $9(0.4)$ \\
\hline Vinchuca (triatomine bug) & $902(100)$ & $1,306(99.0)$ & $2,208(99.4)$ \\
\hline both & 0 & $4(0.3)$ & $4(0.2)$ \\
\hline do not know & 0 & 0 & 0 \\
\hline \multicolumn{4}{|l|}{ Report of Romaña's sign } \\
\hline Yes & 0 & $13(1)$ & $13(0.6)$ \\
\hline No & $902(100)$ & $1,306(99.0)$ & 2,208 (99.4) \\
\hline
\end{tabular}


TABLE II

Profile of conditions for triatomine infestation in the two zones in Cochabamba, Bolivia

\begin{tabular}{|c|c|c|c|}
\hline Parameter & South Zone Valle Hermoso & North Zone Temporal & Total \\
\hline Houses studied [n (\%)] & $902(40.6)$ & $319(59.4)$ & $2,221(100)$ \\
\hline \multicolumn{4}{|l|}{ House condition [n (\%)] } \\
\hline old & $846(93.8)$ & $1,259(95.5)$ & $2,105(94.8)$ \\
\hline new & $56(6.2)$ & $60(4.5)$ & $116(5.2)$ \\
\hline \multicolumn{4}{|l|}{ Floor conditions $[\mathrm{n}(\%)]$} \\
\hline land & $902(100)$ & $41(3.1)$ & $943(42.5)$ \\
\hline covered & 0 & $1,278(96.9)$ & $1,278(57.5)$ \\
\hline \multicolumn{4}{|l|}{ Wall conditions $[\mathrm{n}(\%)]$} \\
\hline mud & $902(100)$ & $62(4.7)$ & $961(43.3)$ \\
\hline mud brick/necks & 0 & $1,257(95.3)$ & $1,260(56.7)$ \\
\hline \multicolumn{4}{|l|}{ Ceiling conditions $[\mathrm{n}(\%)]$} \\
\hline with ceiling/ mud shillings & $66(7.3)$ & $234(17.7)$ & $300(13.5)$ \\
\hline with ceiling/asbestos shillings & 0 & $1,028(77.9)$ & $1,028(46.3)$ \\
\hline without ceiling/mud shillings & $836(92.7)$ & $9(0.8)$ & $845(38)$ \\
\hline without ceiling/ asbestos shillings & 0 & $48(3.6)$ & $48(2.2)$ \\
\hline \multicolumn{4}{|l|}{ Report of animals $[\mathrm{n}(\%)]$} \\
\hline total & 975 (40.4) & $1,437(59.6)$ & $2,412(100)$ \\
\hline in the houses or in dogs & $779(86.6)$ & $1,150(87.2)$ & $1,929(86.97)$ \\
\hline the peri-domicile cats & 0 & $6(0.4)$ & $6(0.27)$ \\
\hline chickens & $79(8.7)$ & $126(9.5)$ & $205(9.24)$ \\
\hline rabbits & $40(4.4)$ & $54(4)$ & $94(4.24)$ \\
\hline cows & $33(3.6)$ & $45(3.4)$ & $78(3.52)$ \\
\hline sheep & $24(2.6)$ & $32(2.4)$ & $56(2.52)$ \\
\hline other & $20(2.2)$ & $24(1.8)$ & $44(1.98)$ \\
\hline Vectors captured (n) & 1,500 & 1,100 & 2,600 \\
\hline Infected triatomine $[\mathrm{n}(\%)]$ & $1,199(79)$ & $410(37)$ & $1,609(61.9)$ \\
\hline
\end{tabular}

ditions, with complete ceilings being mostly absent in the SZ (92.7\%). Taken together, these results indicated that the NZ offered better housing conditions than the SZ.

The presence of domestic animals in the house or in the peri-domicile was also evaluated (Table II). In both the SZ and the NZ, domestic dogs predominated (86.6\% and $87.2 \%$, respectively), but animals raised as sources of food were also frequent: chickens (8-9\%), rabbits (4\%), cows $(3 \%)$, sheep (2-3\%) and other animals such as ducks and pigs were reported. When 145 dogs were sampled and analyzed serologically for the presence of anti-T. cruzi $\operatorname{IgG}$, we observed that $\operatorname{dog}$ seropositivity was $23.5 \%$ in the SZ.

During the course of the study, children were asked to carefully capture bugs in their houses and peri-domestic areas. A total of 1,500 triatomines were collected in the SZ and 1,100 in the NZ (Table II). Children's drawings of their houses and environment (Fig. 4A) and bug collections (Fig. 4B) clearly represent their knowledge of Triatoma infestans (Fig. 4C), which is most likely a result of educational activities carried out in the school to engage the students (Fig. 2A, B). Some children draw triatomines both inside and outside of their houses and some even draw triatomines under the bed or the table (Fig. 4A). We performed direct microscopic examination of salinediluted excrements from the insects to determine the presence of T. cruzi, and this analysis uncovered an important difference in the prevalence of vector infection between the SZ (79\%) and NZ (37\%).
Sero-epidemiological characterization of T. cruzi infection - Since in the SZ, we only evaluated data from children less than 13 years of age, the subsequent studies which aimed to compare NZ to SZ were exclusively performed with data gathered from children between five and 13 years old. The gender distribution in this cohort was similar in both zones (Table III): boys, 50.2 and 54\%, and girls, 49.8 and $46 \%$, respectively, in the SZ and the NZ. Statistically significant differences were observed between seropositivity in children from the two zones by IHA and ELISA: $25 \%$ of the children were found to be serologically positive in the SZ, and $19 \%$ were positive in the NZ (Table III). The distribution of cases by age demonstrated that in the SZ the percentage of seropositive cases was $40 \%$ to $41 \%$ for children between the ages of five to seven and eight to nine, respectively, whereas in the NZ the prevalence was $11 \%$ and $14 \%$ for the same age ranges, indicating that children in the SZ became infected earlier than children in the NZ of CO.

Statistically significant differences were observed between children from the SZ and NZ in the frequency of EKG abnormalities detected: $40 \%$ in the SZ and $17 \%$ in the NZ (Table IV). However, when seropositive cases with EKG abnormalities were compared, a similarly high prevalence of EKG abnormalities was observed in both the SZ (40\%) and NZ (53\%, Table IV). Table V details the types of EKG abnormalities observed in the Bolivian children involved in this study. The most frequent finding was Incomplete Right Bundle Branch Block (IRBB), 


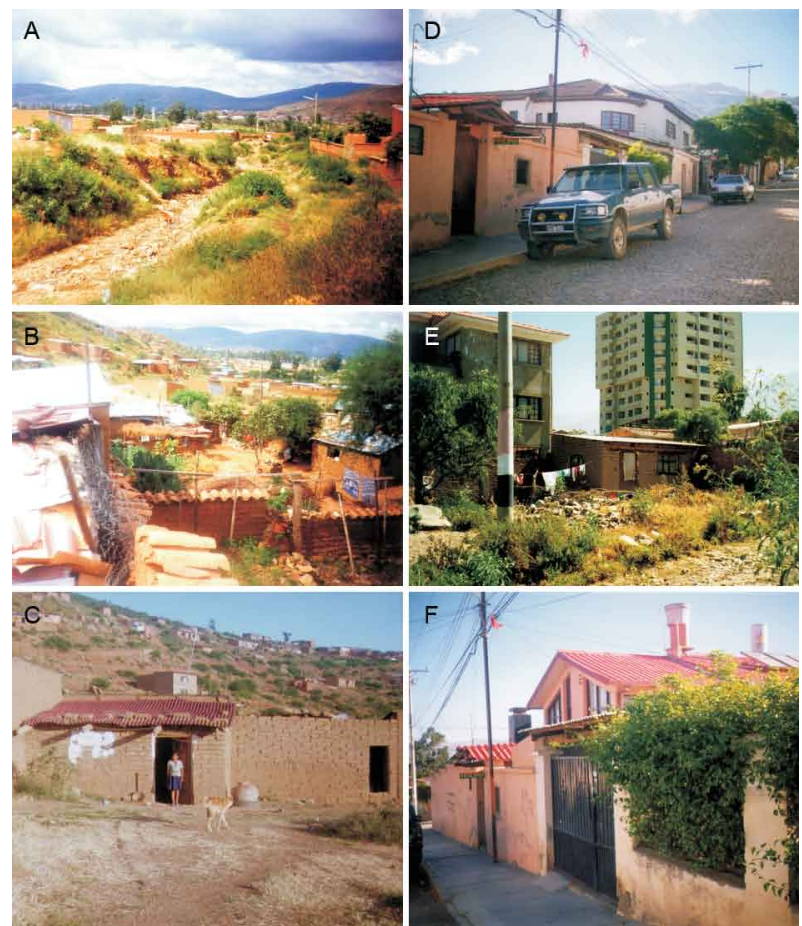

Fig. 3: general aspects of the housing conditions in districts of Cochabamba, Bolivia. A-C: South zone; D-F: North zones.

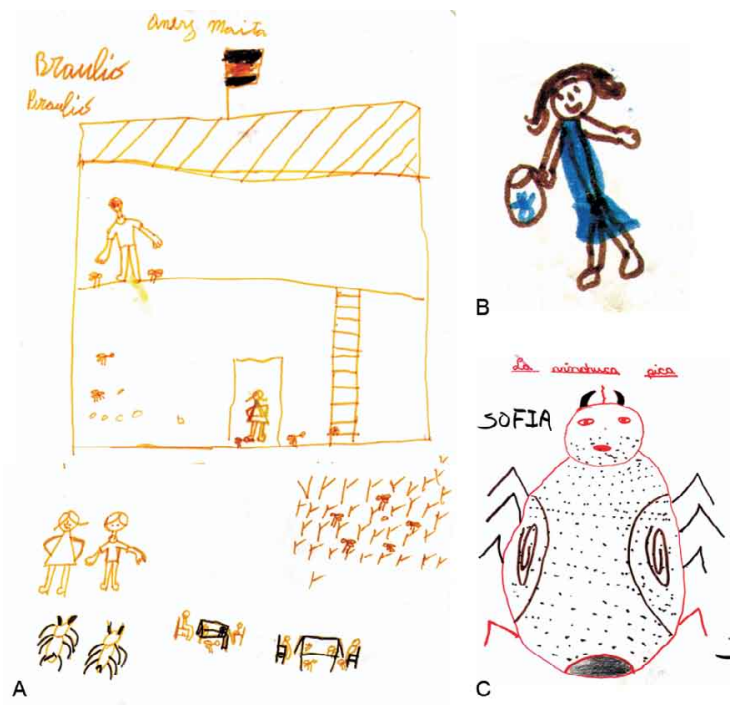

Fig. 4: draws made by Bolivian children related to triatomine knowledge.

which accounted for $22.7 \%$ and $32.4 \%$ of the recorded abnormalities in seropositive children in the SZ and NZ, respectively. It is interesting to note that the percentage of seronegative children with IRBB was $24.3 \%$ in the SZ, whereas in the NZ, only $5 \%$ of seronegative children were determined to have this condition. In some children IRBB was associated with other electrophysiological abnormalities, such as left hemiblock or left shift on the electric axis. Hemiblock findings accounted for less than $5 \%$ of EKG abnormalities. Alterations in cardiac rhythm frequency (relative bradicardia or sinus tachy-
TABLE III

Epidemiological characterization of the Chagas disease infection in two zones of an urban area in Cochabamba, Bolivia

\begin{tabular}{cccc}
\hline Parameter & $\begin{array}{c}\text { South Zone } \\
\mathrm{n}(\%)\end{array}$ & $\begin{array}{c}\text { North Zone } \\
\mathrm{n}(\%)\end{array}$ & $\begin{array}{c}\text { Total } \\
\mathrm{n}(\%)\end{array}$ \\
\hline Cases studied & 902 & 929 & $1,831(100)$ \\
Sex: male & $453(50.2)$ & $503(54)$ & $956(52)$ \\
$\quad$ females & $449(49.8)$ & $426(46)$ & $875(48)$ \\
Age (mean $\pm \mathrm{sd})$ & $8.2 \pm 1.7$ & $10.1 \pm 2.2^{a}$ & $9.1 \pm 2.22$ \\
Age (all) $5-13$ & $902(100)$ & $929(100)$ & $1,831(100)$ \\
$5-7$ & $324(35.9)$ & $134(14.4)$ & $458(25)$ \\
$8-9$ & $332(36.8)$ & $289(31.1)$ & $621(34)$ \\
$10-11$ & $221(24.5)$ & $175(18.8)$ & $396(22)$ \\
$12-13$ & $25(2.8)$ & $331(35.6)$ & $356(19)$ \\
Seropositive ${ }^{b}$ & $225(25)^{a}$ & $176(19)^{a}$ & $401(22)$ \\
Seronegative $\mathrm{e}^{b}$ & $677(75)$ & $753(81)$ & $1430(78)$ \\
Seropositive & & & \\
$5-13$ & $225(100)$ & $176(100)$ & $401(100)$ \\
$5-7$ & $90(40)$ & $20(11)$ & $110(27)$ \\
$8-9$ & $93(41)$ & $25(14)$ & $118(29)$ \\
$10-11$ & $41(18)$ & $55(31)$ & $96(24)$ \\
$12-13$ & $1(0)$ & $76(43)$ & $77(19)$ \\
\hline
\end{tabular}

$a$ : significant differences $(\mathrm{p}<0.05)$ between South and North zones. $b$ : IHA and ELISA.

TABLE IV

Clinical and electrocardiographic characterization of $T$. cruzi infection in two zones of an urban area in Cochabamba, Bolivia

\begin{tabular}{lccr}
\hline Parameter & $\begin{array}{c}\text { South Zone } \\
\mathrm{n}(\%)\end{array}$ & $\begin{array}{c}\text { North Zone } \\
\mathrm{n}(\%)\end{array}$ & $\begin{array}{c}\text { Total } \\
\mathrm{n}(\%)\end{array}$ \\
\hline Cases studied & $902(40.5)$ & $929(59.5)$ & $1,831(100)$ \\
EKG profile & & & \\
$\quad$ EKG normal & $541(60)$ & $772(83)$ & $1,313(72)$ \\
$\quad$ EKG abnormal & $361(40)^{a}$ & $157(17)^{a}$ & $518(28)$ \\
Seropositeve & & & \\
$\quad$ EKG normal & $134(60)$ & $83(47)$ & $217(54)$ \\
$\quad$ EKG abnormal & $91(40)$ & $93(53)$ & $184(46)$ \\
Seronegative & & & \\
$\quad$ EKG normal & $407(60)$ & $689(91.5)$ & $1,096(77)$ \\
EKG abnormal & $270(40)$ & $64(8.5)$ & $334(23)$ \\
\hline
\end{tabular}

$a$ : significant differences $(\mathrm{p}<0.05)$ between South and North zones.

cardia) were also detected at a low prevalence. Ventricular overload, either left or right, was rarely observed.

Analysis of risk factors - To uncover the factors that might explain the differing infection levels in the two zones studied, we performed a chi-square analysis of the two zones based on the age groups of five to nine years old and 10 to 13 years old (Table II). In this analysis, factors identified as potentially influencing the risk of infection included sex, type of floor, type of walls, presence of ceiling, dogs in the house, presence of other 


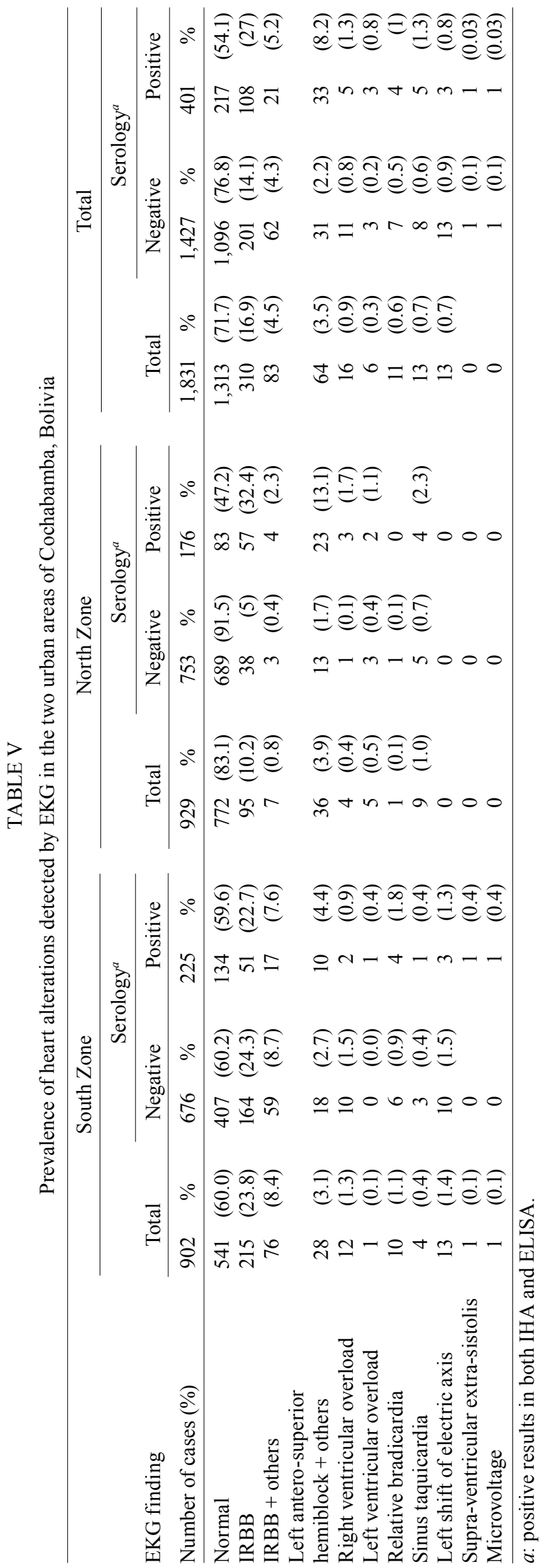

animals etc. These factors were determined not to significantly impact infection. However, when age was evaluated, a striking difference was observed. In the SZ, $25 \%$ of children between the ages of five and nine were infected, while in the NZ, this percentage was $14.5 \%$. However, age was not determined to be a significant factor in infection when the group of individuals aged 10 to 13 was compared between the two zones. In the SZ, $19 \%$ of the individuals 10 to 13 years old were infected, while in the NZ, the percentage was $22 \%$. Analysis of the odds ratio of an individual being seropositive in the $\mathrm{NZ}$ and the SZ was quite distinct: in the SZ, children of 10 to 13 years old demonstrated a lower risk of infection (odds ratio of 0.536) than children in the NZ, where the risk of infection was almost three times higher with an odds ratio of 2.93 .

\section{DISCUSSION}

This paper describes both qualitative and quantitative evidence for the presence of active transmission of T. cruzi in the urban area of CO during the period studied. We demonstrate that $T$. cruzi infection is a serious health problem in $\mathrm{CO}$, and this infection is not restricted to rural areas or small villages in Bolivia. Furthermore, we demonstrate that a very young population (5 to 9 years old) is under a higher risk of infection in one of the two zones studied, while in another zone the highest risk occurs in individuals of the age group of 10 to 13 years old. Our data show that EKG abnormalities are prevalent in children and pre-adolescents, suggesting that the Bolivian population is under continuous exposure to T. cruzi infection and re-infection. This may have significant consequences in inducing the severe form of the disease, which appears to develop early in life in this population.

It was shown that in the $\mathrm{CO}$ area, wild infestation and a close proximity to human may increase the infectivity of $T$. cruzi due to a triatomine feeding preference. Similar information is presented in the Chagas disease review (Guillén 2002). In this context, Guhl (2007) also discusses the difficulties related to understanding the epidemiology of vector distribution, control, and domestication, and describes that proper understanding of these dynamics will certainly impact disease transmission and prevalence in the most endemic areas.

It is clear from the data presented in Table I that the SZ and NZ population of CO is quite knowledgeable of Chagas disease and its vector, although they are uncertain as to how the disease is transmitted. A study in Argentina showed that evidence-based knowledge about Chagas disease is limited (Sanmartino \& Crocco 2000). It has been well-demonstrated that poor housing conditions are critical in facilitating the inhabitance of triatomines in domiciles (Dias \& Schofield 1999). In our studies focusing on the two areas of $\mathrm{CO}$ we did not observe this correlation, and only housing conditions were determined not to impact the prevalence of infection and could not be considered a risk factor for the population. A similar number of triatomines were captured in both zones, indicating that a simple difference in housing conditions was not sufficient to account for the differences in risk of infection. The homes with mixed characteristics in 
the NZ, such as shown in Fig. 3E, could account for the presence of triatmine proliferation areas in this region.

Seropositivity for T. cruzi was as high as $25 \%$ and was observed in children between five to 13 years of age living in the peripheral districts of $\mathrm{CO}$. This infection rate is alarming and indicates a dynamic condition of active and continuous transmission of the infection through the human population. Although it is tempting to speculate that high rates of seropositivity may be associated with precarious housing conditions, a high percentage of comorbid $T$. infestans infections in the population, or the presence of animals in the household, these relationships were not found to be statistically significant. It is also possible that the level of triatomine infection was underestimated in our study especially given that it was recently shown that, newer and more sensitive PCR reveals significantly higher rates of $T$. cruzi infection than microscopy (Pizarro et al. 2007). Also, children in this study may have acquired an infection outside of the $\mathrm{CO}$ region and therefore may not be autochthonous cases of the disease. This, however, does not exclude the fact that urban transmission was occurring at the time of this study.

It is interesting to note that although the infection rate was high in the populations of both the SZ and NZ, seropositivity in different age groups was quite distinct. While in the SZ the majority of children infected were between the ages of five and nine, in the NZ the highest percentage was in the age group of 10 to 13 years old, indicating that younger children living in the SZ had a higher risk of infection. There are several explanations for this observation. First, the SZ is a new settlement and individuals living in this area came from regions of the country where Chagas disease is not prevalent and, therefore, the newly-exposed individuals are more susceptible to infection. The acute phase of infection is more severe and, consequently the chances of developing myocardiopathy are higher. It is difficult to determine whether this is due to differences in induction of the immune response early in life as previously described (Eloi-Santos et al. 1989, Neves et al. 1999), so data obtained from these studies may be highly speculative. Furthermore, it is possible that the decreased risk observed in the older age groups in the SZ may be secondary to the development of an effective immune response against the parasite. Further studies on the immune responses of children and adults from these two areas will be of major importance in understanding the mechanisms behind differing immunity. Another plausible alternative explanation may be differences in parasite and host genetics, which is an interesting question that should be addressed in this population. In the rural village of Mizque, which is also in the department of Cochabamba (Brenière et al. 2002), the two main lineages of $T$. cruzi are present (T. cruzi I and II, clones 20 and 39). It is clear that factors related to host immune response are not sufficient to explain the differences observed between the age groups in the two areas of CO. Genetic factors, both of the host and of the parasite, are also of major importance in determining the outcome of infection and deserve further investigation.

Diagnosis of acute Chagas disease is still difficult, and the currently available methods either have low sen- sitivity and/or specificity or are too expensive to be used in the field. The results presented in this paper demonstrate that, in the two urban zones of $\mathrm{CO}$, the prevalence of Chagas disease is quite high when measured by IHA and ELISA. These are the methods most commonly applied in Bolivia, however, the percentage of infected population may be even higher since these assays may underestimate the actual prevalence of infection. In a previous publication, we confirmed that PCR is able to detect acute infection by $T$. cruzi even when specific antibodies are not yet produced, and anti-galactose IgG can be used as an indicator for the presence of parasite (Antas et al. 1999). These results may also explain the discrepancies in positivity rates observed between the age groups in the two areas of CO.

Although this paper raises more questions than it answers regarding the epidemiology of Chagas disease, it does present an interesting and novel description of active transmission of $T$. cruzi and the incidence of this infection in urban $\mathrm{CO}$, as well as providing insights into the causes of early myocardiopathy. These results contrast significantly with previously published data (Salinas-Salomon 1999) and well-accepted studies describing development of severe heart disease primarily in individuals who have been infected with T. cruzi for over 30 years (Dias et al. 1956, Araujo et al. 1985, Prata 1999). Future genetic studies on the parasite strains and on the population in general using specific molecular and immunological markers may provide a better understanding of the striking differences in the CO population and may help determine whether this characteristic is exclusive to the Bolivian population.

\section{ACKNOWLEDGMENTS}

To the technical personal from the Inmunoparasitology, Chagas Laboratory from the Biology Department, the San Simón University, for helping in IHA and ELISA, Medrano brothers, medicine and biology students, School supervisors, parents and children from the both schools, for helping during the field work, and Dr. Olindo Assis Martins Filho and Faustino Torrico, for critical discussion of the results.

\section{REFERENCES}

Antas PRZ, Medrano-Mercado N, Torrico F, Ugarte-Fernandez R, Gómez F, Correa Oliveira R, Chaves AC, Romanha AJ, AraújoJorge TC 1999. Early, intermediate and late acute stages in Chagas' disease: a study combining anti-galactose IgG quantitation, specific serodiagnosis and polymerase chain reaction analysis. Am J Trop Med Hyg 61: 308-314.

Arata AA, Balderrama F, Bermudez H, Navin T, Ormsby G, Torrico F, Velarde R 1994. Trabajo de la SNS CCH/Programa Piloto de Control de Chagas. La Paz, Bolivia, Ministerio del Desarollo Humano, Secretaria Nacional de Salud, 94 pp.

Araujo RC, Bestetti RB, Godoy RA, Oliveira JS 1985. Chronic Chagas heart disease in children and adolescents: a clinicopathologic study. Int J Cardiol 9: 439-445.

Bailey-Lazcano R C, Trewhella-Fernandez EN 1998. Identidad familiar, migración y desnutrición: las vicisitudes de la dinámica identidaria familiar ante la migración: identidad familiar y desnutrición, Thesis, UMSS, Cochabamba, Bolivia, 78 pp.

Blanes J 2006. Bolívia: las áreas metropolitanas en perspectiva de desarrollo regional. Rev Eure (Santiago de Chile) 32: 21-36. 
Brenière SF, Bosseno MF, Noireau F, Yacsik N, Liegeard P, Aznar C, Hontebeyrie M 2002. Integrate study of a Bolivian population infected by Trypanosoma cruzi, the agent of Chagas Disease. Mem Inst Oswaldo Cruz 97: 289-295.

Calderon GF, Toranzos C 1984. Urbanización y Etnicidad. El caso de La Paz. Cochabamba, CERES, 65 pp.

Carrasco R, Miguez H, Camacho C, Echalar L, Revollo S, Ampuero T, Dedet JP 1990. Prevalence of Trypanosoma cruzi in blood banks of seven departments of Bolivia. Mem Inst Oswaldo Cruz 85: 69-73.

Cortez MR, Pinho AP, Cuervo P, Alfaro F, Solano M, Xavier SC, D'Andrea PS, Fernandes O, Torrico F, Noireau F, Jansen AM 2006. Trypanosoma cruzi (Kinetoplastida Trypanosomatidae): ecology of the transmission cycle in the wild environment of the Andean valley of Cochabamba, Bolivia. Exp Parasitol 114: 305-313.

Dias E, Laranja FS, Miranda A, Nobrega G 1956. Chagas' disease. A clinical, epidemiologic and pathologic study. Circulation 14: 1035-1060.

Dias JCP 2007. Southern Cone Initiative for the elimination of domestic populations of Triatoma infestans and the interruption of transfusional Chagas disease. Historical aspects, present situation, and perspectives. Mem Inst Oswaldo Cruz 102 (Suppl. I): 11-18.

Dias JCP, Schofield CJ 1999. The evolution of Chagas disease (American Trypanosomiasis) control after 90 years since Carlos Chagas discovery. Mem Inst Oswaldo Cruz 94: 103-121.

Eloi-Santos SM, Novato-Silva E, Maselli VM Gazzinelli G, Colley DG, Correa-Oliveira R 1989. Idiotypic sensitization in utero of children born to mothers with Schistosomiasis or Chagas' disease. J Clin Invest 84: 1028-1031.

Guhl F 2007. Chagas disease in the Andean countries. Mem Inst Oswaldo Cruz 102: 29-37.

Guillén G 2002. El control de la enfermedad de Chagas en Bolivia. In AC Silveira (org.) El control de la enfermedad de Chagas en los paises del Cono Sur de América: historia de una iniciativa internacional, 1991/2001, PAHO E-book. Available from: http://www. paho.org/portuguese/ad/dpc/cd/dch-historia-incosur.PDF.

INE - Instituto Nacional de Estadística 2001. Censo de Población y Vivienda. Bolivia. Available from: http://www.ine.gov.bo/cgibin/Redatam/RG4WebEngine.exe/PortalAction.

Laserna $\mathrm{R}$ 1995. Coca cultivation, drug traffic and regional development in Cochabamba, Bolivia, PhD Thesis, University of California, Berkeley, 125 pp.
Ledo MC, Zelada O 1989. Población, migración y empleo en Cochabam$b a$, Centro de Estudios de la Población, CEP, Cochabamba, 78 pp.

Neves SF, Elói-Santos S, Ramos R, Rigueirinho S, Gazzinelli G, Correa-Oliveira R 1999. In utero sensitization in Chagas disease leads to altered lymphocyte phenotypic patterns in the newborn cord blood mononuclear cells. Parasite Immunol 21: 631-639.

Noireau F 1999. La enfermedad de Chagas y sus particularidades epidemiológicas en Bolivia. In R Al Cassab, F Noireau F, G Guillén (eds.), Chagas, la enfermedad en Bolivia: conocimientos científicos al inicio del programa de control (1998-2002), Primera, La Paz, p. 17-47.

Pizarro JC, Lucero DE, Stevens L 2007. PCR reveals significantly higher rates of Trypanosoma cruzi infection than microscopy in the Chagas vector, Triatoma infestans: High rates found in Chuquisaca, Bolivia. BMC Infect Dis 7: 66.

Pless M, Juranek D, Kozarsky P, Steurer F, Tapia G, Bermudez H 1992. The epidemiology of Chagas disease in a hyperendemic area of Cochabamba, Bolivia: A clinical study including electrocardiography, seroreactivity to Trypanosoma cruzi, xenodiagnosis, and domiciliary triatomine distribution. Am J Trop Med Hyg 47: 539-546.

Prata A 1999. Evolution of the clinical and epidemiological knowledge about Chagas Disease 90 Years After its Discovery. Mem Inst Oswaldo Cruz 94 (Suppl. I): 81-88.

Salinas-Salomon CE 1999. La cardiopatia chagasica crónica. In: R Al Cassab, F Noireau F, G Guillén (eds.), Chagas, la enfermedad en Bolivia: conocimientos cientificos al inicio del programa de control (1998-2002), Primavera, La Paz, p. 49-58.

Sanmartino M, Crocco L 2000. Knowledge about Chagas' disease and risk factors in Argentina communities with different epidemiological trends. Rev Panam Salud Publica 7: 173-178.

SNS - Secretaria Nacional de Salud 1994. Chagas, en Bolivia: el trabajo del programa piloto de control SNS/CCH. Ministerio de Desarrollo humano, La Paz, Bolivia, 94 pp.

Sostres MF, Delgado SN 1993. Diagnostico socioeconómico y demandas educativas: Villa Venezuela, Valle Hermoso y Santa Veracruz, Proyecto de implantación, 95 pp.

Valencia A. Investigación epidemiológica nacional de la Enfermedad de Chagas. In Ministerio de Previsión Social y Salud Pública, La Paz, Bolivia, 1990, 184 pp.

WHO - World Health Organization 2002. Control of Chagas Disease, WHO Technical Report Series 811, Geneva. Available from: http://whqlibdoc.who.int/trs/WHO_TRS_905.pdf. 